\title{
The Design of Mooring Dolphin Layout and Mooring Line Tension Analysis
}

\author{
Sholihin $^{\mathrm{a}}$, Yoffan Ramadhan ${ }^{\mathrm{b}}$ and Haryo D Armono ${ }^{\mathrm{c}^{*}}$ \\ a) Lecturer, Department of Ocean Engineering, Institut Teknologi Sepuluh Nopember, Kampus ITS - Sukolilo, Surabaya 60111, Indonesia \\ b) Student, Department of Ocean Engineering, Institut Teknologi Sepuluh Nopember, Kampus ITS - Sukolilo, Surabaya 60111, Indonesia \\ c) Associate Professor, Department of Ocean Engineering, Institut Teknologi Sepuluh Nopember, Kampus ITS - Sukolilo, Surabaya 60111, \\ Indonesia \\ *Corresponding author: armono@oe.its.ac.id
}

\begin{abstract}
Some marine industries choose to set up their activities in the coastal area northern part of Java Island, Indonesia, by considering the calmness of the Java Sea environment. A special terminal for liquid bulk cargo to transport fuel oil is being planned for construction in Sedayu Lawas village, Lamongan district, East Java Province. The ship carrying cargo oil require a pier and jetty in sufficient depth for loading and unloading. The jetty need to be enhanced to support more equipment for ship to port, which include breasting dolphin, mooring dolphin, trestle, and causeway. In this respect a study is carried out to review the stress analysis of the mooring lines (ropes) attached to jetty for various mooring dolphin layout and arrangements. The metocean data such as wind and tides in the areas were processed and analyzed. The layout of the ship and mooring dolphin rope angle were designed in accordance with OCIMF code. The stress analysis of mooring rope for various layout mooring dolphin has been analyzed to determine whether the design layout is safe during operation. The rope stress were analyzed using time domain dynamic analysis for 10,800 seconds. The safety of ship during loading for various rope condition were presented. It is suggested that all ropes should be attached to mooring dolphin for ship and port safety.
\end{abstract}

Keywords: mooring dolphin, design, mooring tension

\section{INTRODUCTION}

Due to the need to maintain a berthing ship stay in position while transferring cargo oil at the port, then a well arranged mooring system with sufficient strength is needed. The mooring system consists of breasting dolphin and mooring dolphin, as shown in Fig. 1. Breasting dolphin serve to withstand the impact of the ship, while the mooring dolphin functions to hold the pull force of the ship when it is docked.

Due to the large variation in the ship sizes expected to be served by this dolphin, i.e. ranging from 1,000 DWT up to $50,000 \mathrm{DWT}$, it is necessary to design the appropriate mooring dolphin for ships that will be berthed. In addition it is necessary to analyze the mooring stress to assure the designed rope for mooring dolphin will have adequate strength to withstand largest tension load and hence safe during the entire operation in long period.

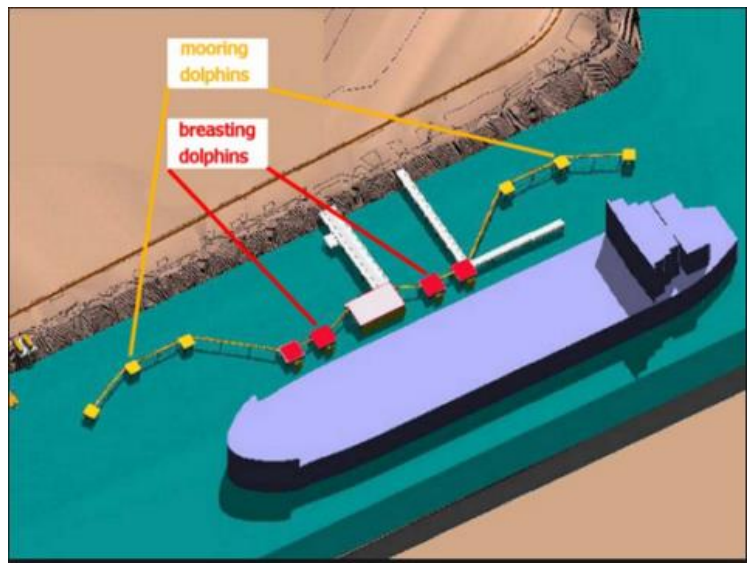

Figure 1. Breasting dolphin and mooring dolphin [1]

\section{MATERIALS AND METHODS}

Stages in the analysis are carried out as described in the following.

\subsection{Literature Study}

Literature study is performed by exploring books, theses, journals, codes/standards, legislation/regulations obtained from both national and international resources. Further, the activity include also learning the softwares to be used, covering the general floating structure design, motion in frequency domain, dynamic analysis in the time domain.

\subsection{Data Collection}

The data to be prepared for the analysis may be found from literature study or field study. Field study is conducted by direct observation of the object to be examined, exploration on some of the data required in accordance with the issues 
to be examined and the implementation of this study. The primary data required are as follows:

- Main dimension data of the ships

- Wind data

- Tidal data

- Flow data

- Bathymetry data.

\subsection{Wind Data Processing}

Wind data processing is intended to obtain the value of wind speed and direction of winds that blow on the location of mooring dolphin. This can then be used to determine the effective fetch. Wind data that has been processed and may further be used to calculate wave parameters, namely wave heights and return periods.

\subsection{Tidal Forecasting}

The tidal data forecasting is established on the basis of the field observation especially on the periodical high and low tides. It aims at obtaining the components of tides and tidal elevation. The least squares method is applied in this research.

\subsection{Design Elevation of Mooring Dolphin}

Elevation is calculated from the pier on the predictions of tidal water level, reference tidal datum and wave heights as well as the predetermined clearance of $1.5 \mathrm{~m}[2,3]$. As for determining the minimum depth of the pier, a factor which became the main parameter is the high laden water on ships in operation and a minimum height of receding waters. The factors are used in determining the depth of the location of the pier so that ships to be docked at the pier will not touch the seabed due to the depth of less than it is needed.

\subsection{Design Configuration of Mooring Dolphin}

Design configuration of mooring dolphin made based on the existing provisions in the applicable standard or code, such as OCIMF [2], fixed mooring design manuals, etc.

\subsection{Ship Modeling}

The initial ship structure modeling is performed using a ship design software. Modeling is aimed at finding the ship hydrostatic data to be validated by the data stability booklet. Further, modeling is carried by hydrodynamic software to obtain RAO, wave drift, added mass and damping force that will be used as input for modeling further by using analysis software based dynamic time domain, with different directions heading the environmental load $\left(0^{\circ}, 180^{\circ}\right.$, and $270^{\circ}$ ).

\subsection{Analysis of Tension of Mooring Rope}

Mooring lines stress analysis is conducted to obtain value of tension or maximum tensile stress. For determining the safety of mooring lines during operation it is necessary to find the ratio of MBL (Minimum Breaking Load) of the rope against the maximum operational tension value of the analysis results. The MBL mooring rope, made of nylon, must be greater than the maximum operating tension by the factor of 2.2.

\subsection{Analysis of the Tension when a Mooring Line Disconnected}

This analysis is conducted to observe the safety of mooring dolphin configuration when one or a number of mooring ropes are disconnected.

\section{RESULTS AND DISCUSSION}

\subsection{Wind Rose and Fetch}

To facilitate in determining the speed and direction of the wind, the wind data was processed in the form of wind rose. The result of such an analysis is presented in Fig. 2. It is shown that the prevailing wind came from Southeast and North West with the maximum speed in the range of 7.5$10.0 \mathrm{~m} / \mathrm{s}$. However, the wind direction considered for fetch analysis was Northwest since the Southeast area was mainly land.

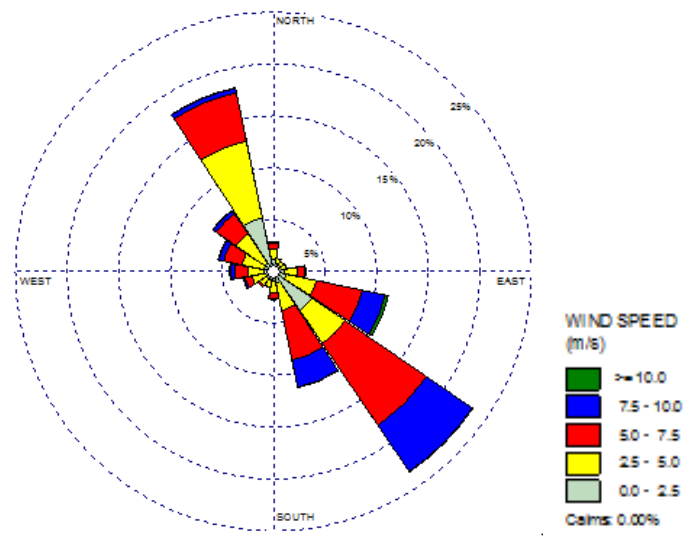

Figure 2. Chart of wind rose year $2005-2015$

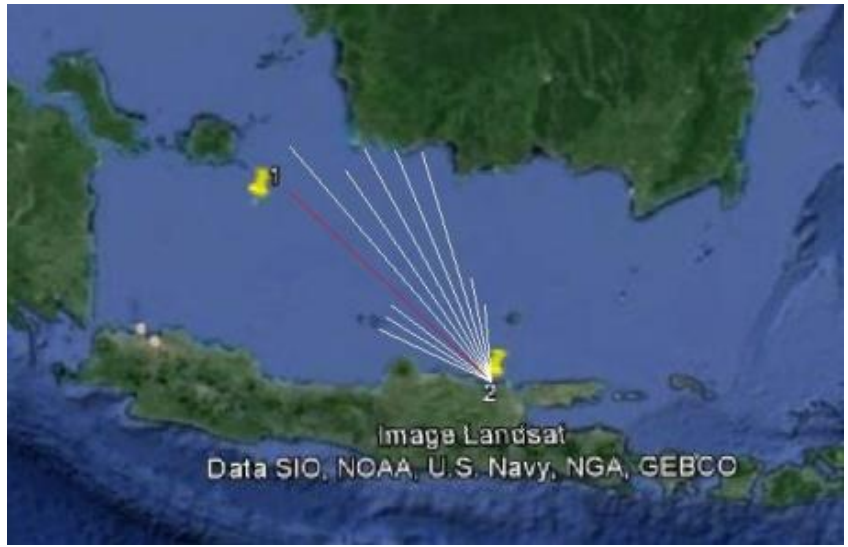

Figure 3. Area of fetch propagation [4]

Further, the wind data was also processed to generate the fetch length information, as exhibited in Fig. 3. For the current study an effective fetch with length of about $235 \mathrm{~km}$ is attained. The prevailing wind direction for effective fecth 
estimation was Northwest, following the chart of wind rose in Fig 2 above.

\subsection{Wave Data and Return Period}

Wind data has been processed and applied to predict the wave parameters following CERC [5,6]. The results as listed in Table 1 comprise of wave return periods from 5 up to 100 years and the corresponding significant wave heights.

Table 1.Wave return period and heights

\begin{tabular}{|c|c|}
\hline Period (year) & $H s(\mathrm{~m})$ \\
\hline 5 & 3.42 \\
\hline 10 & 3.69 \\
\hline 15 & 3.84 \\
\hline 20 & 3.95 \\
\hline 25 & 4.03 \\
\hline 50 & 4.29 \\
\hline 100 & 4.54 \\
\hline
\end{tabular}

\subsection{Tide Forecasting}

The least square method has been employed in the tide forecasting. In this respect results of the forecasting in term of the tide components are given in Table 2. Figure 4 shows the water fluctuation level during tides observation. It is seen from Fig. 4 the types of tides was mixed tide prevailing diurnal tide.

Table 2. Tide components

\begin{tabular}{|c|c|c|c|c|c|c|c|c|c|}
\hline SO & M2 & S2 & K1 & O1 & N2 & K2 & P1 & M4 & Ms4 \\
\hline 1.2 & 0.04 & 0.21 & 0.2 & 0.2 & 0.2 & 0.18 & 0.47 & 0.01 & 0.0 \\
\hline
\end{tabular}

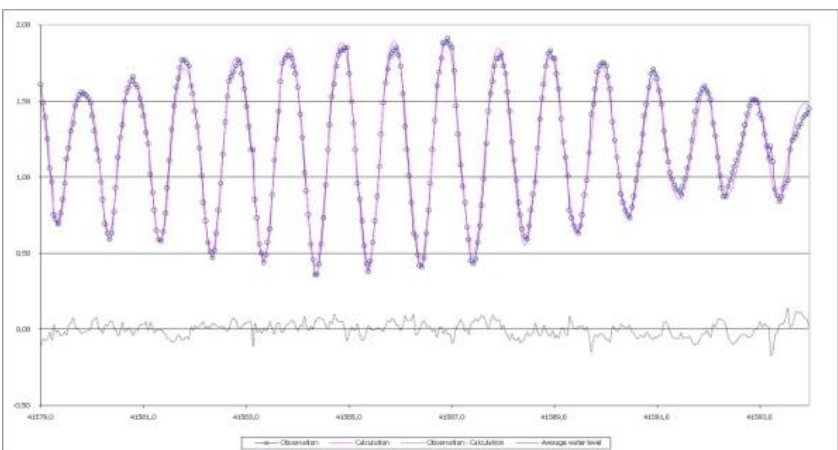

Figure 4. Tide forecasting

From the values of tide components in Table 2 further parameters can be derived as follows:
$\mathrm{HHWS}=\mathrm{So}+(\mathrm{M} 2+\mathrm{S} 2+\mathrm{K} 1+\mathrm{O} 1+\mathrm{K} 2+\mathrm{P} 1) \quad=2.5 \mathrm{~m}$
MHWS $=$ So $+(\mathrm{M} 2+\mathrm{S} 2+\mathrm{O} 1)$
$=1.6 \mathrm{~m}$
MSL $=$ So
$=1.2 \mathrm{~m}$
MLWS $=$ So $-(\mathrm{M} 2+\mathrm{S} 2+\mathrm{O} 1)$
$=0.8 \mathrm{~m}$
$\mathrm{LLWS}=\mathrm{So}-(\mathrm{M} 2+\mathrm{S} 2+\mathrm{K} 1+\mathrm{O} 1+\mathrm{K} 2+\mathrm{P} 1)=-0.1 \mathrm{~m}$
where HHWS stands for Highest High Water Spring, MHWS is Mean High Water Spring, MSL stand for Mean Sea Level, MLWS is Man Low Water Spring and LLWS is the Lowest Low Water Spring.

\subsection{Elevation of Mooring Dolphin}

In this study the LLWS water level regarded as determining the elevation datum [7]. Therefore, all the tides parameters were added by $0.1 \mathrm{~m}$. The maximum elevation of mooring pile for $4.5 \mathrm{~m}$ significant wave height and $2.6 \mathrm{~m}$ HHWS and $1.5 \mathrm{~m}$ freeboard according to OCIMF was calculated as follows:

HHWS $+1 / 2 \mathrm{Hs}+1.5$ (freeboard according to OCIMF)

$$
\begin{aligned}
& =2.6+2.25+1.5 \\
& =6,35 \mathrm{~m} \text { from LLWS (datum) }
\end{aligned}
$$

As for the depth of the mooring dolphin is calculated by considering the largest loaded from ships to be berthed. If a laden ships of 50,000 DWT having a characteristic draft of $12 \mathrm{~m}$, then the minimum draft of the mooring dolphin is calculated as follows:

Minimum draft $=1.1 \times$ Ship draft

Minimum draft $=1.1 \times 12$

Minimum draft $=13.2 \mathrm{~m}$ of HHWS

Tolerance Freedom $=1 \mathrm{~m}$

Final minimum draft $=-14.2 \mathrm{~m}$ from LLWS (datum)

Considering the above values, the design elevation of the mooring dolphin is then visualized as in Fig. 5.

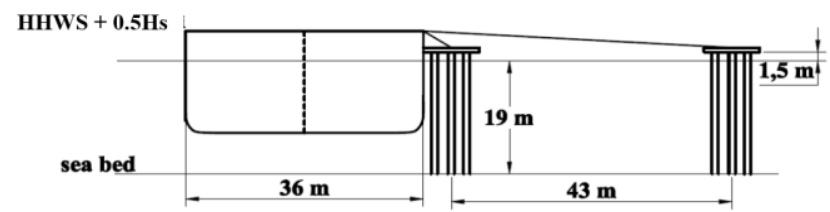

Figure 5. Elevation of the mooring dolphin

\subsection{Mooring Dolphin Configuration}

There are several criteria that must be met in the design the configuration of mooring dolphin [3] namely:

- Maximum horizontal angle from the bow and stern line to the line perpendicular of the bilge is of $45^{\circ}$

- Maximum horizontal angle between the breast line to the line perpendicular of the hull of $15^{\circ}$

- Maximum horizontal angle of spring line against the hull is $10^{\circ}$

- Maximum vertical angle of a mooring line to the ships is $25^{\circ}$

- The distance between the berthing dolphin is $0.3 \mathrm{LOA}$

- The distance between the structures platform and the highest maximum water level is $1.5 \mathrm{~m}$

- The distance between the ship to the mooring dolphin ranges between $30 \sim 50 \mathrm{~m}$

- The maximum number of mooring dolphin in one configuration is 6

- The maximum number breasting dolphin in one configuration is 4

Due to the relatively large variation of the vessel size, then it is not possible to make all configuration in one mooring dolphin. Therefore, the overall configuration of mooring dolphin is divided into three segments, as exhibited 
in Fig. 6. The figure shows three different berthing combination for ships size 1,000 - 5,000 DWT, 5,00010,000 DWT and 10,000 - 50,000DWT, respectively. Therefore, there are three terminal or three mooring dolphin configuration prepared for services vessel in one jetty. Due to limited space in this paper, only the result of mooring configuration for $10,000-50,000 \mathrm{DWT}$ will be presented.

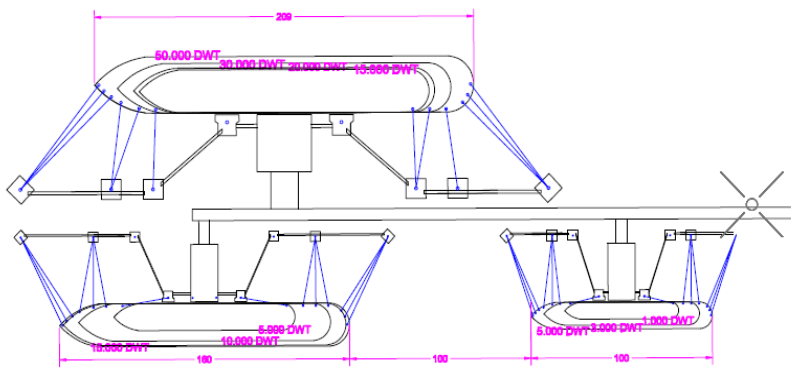

Figure 6. The overall three mooring dolphin configuration

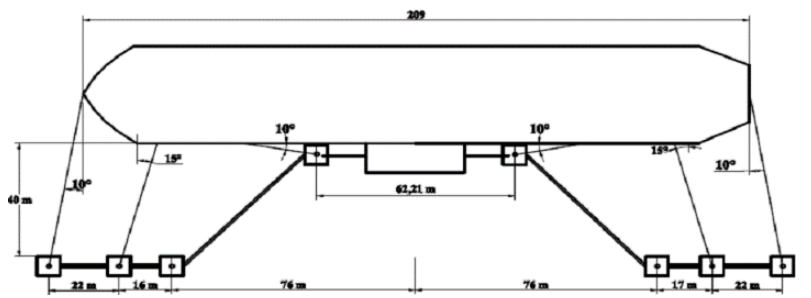

Figure 7. Example of detail design of mooring dolphin configuration for 50,000 DWT (top view)

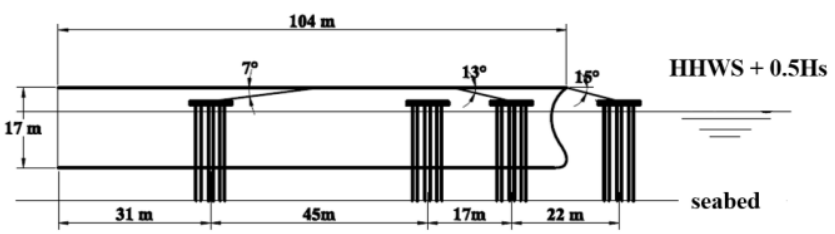

Figure 8. Example of detail design of mooring dolphin configuration for 50,000 DWT (side view)

\subsection{Result of Ship Modeling}

Modeling of the ship is performed using hydrodynamic software based 3-D diffraction theory and by considering the data of loading, environmental and technical drawing [8]. This modeling generates the hull form and panelization as shown in Fig. 9.

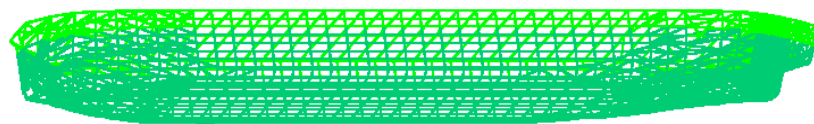

Figure 9. The hull model of a 50,000 DWT ship

\subsection{Ship RAO Analysis}

RAO of ship motion behavior was computed using the hydrodynamic software for wave directions of $0^{\circ}, 45^{\circ}, 90^{\circ}$, $135^{\circ}$ and $180^{\circ}$. In the case of a 50,000 DWT tanker, as can be seen in Fig. 10, the largest surge motion occurs in the wave heading $0^{\circ}$ and $180^{\circ}$. For sway motion, the largest intensity is due to the $90^{\circ}$ wave, as indicated in Fig. 11. Further, as shown in Fig. 12, the largest heave motion occurs also in $90^{\circ}$ wave direction. Among the three translational modes, the peak of heave RAO motion eventually is the largest, that is in the order of $1.473 \mathrm{~m} / \mathrm{m}$. While the peak of surge and sway RAOs are only approaching $1.0 \mathrm{~m} / \mathrm{m}$.

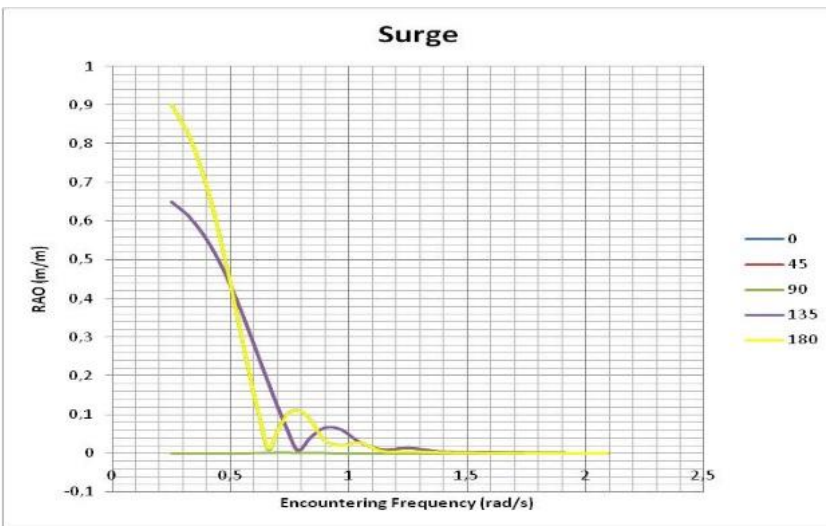

Figure 10. Surge RAO of a 50,000 DWT tanker

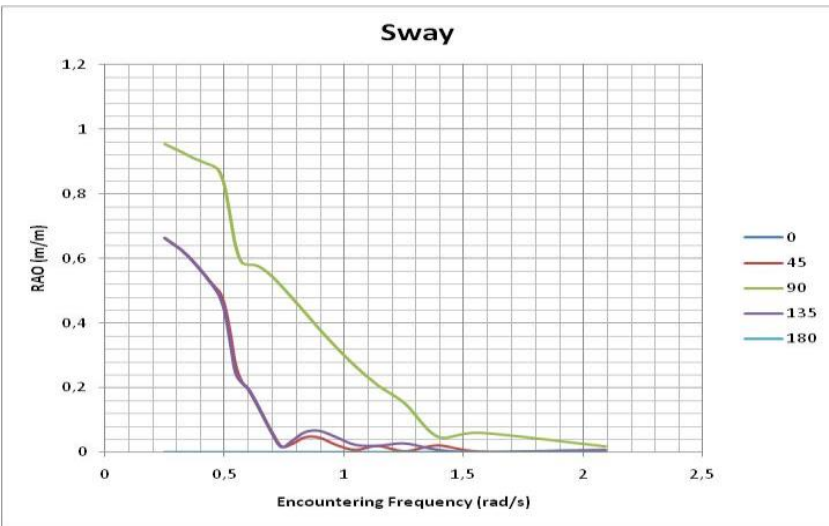

Figure 11. Sway RAO of a 50,000 DWT tanker

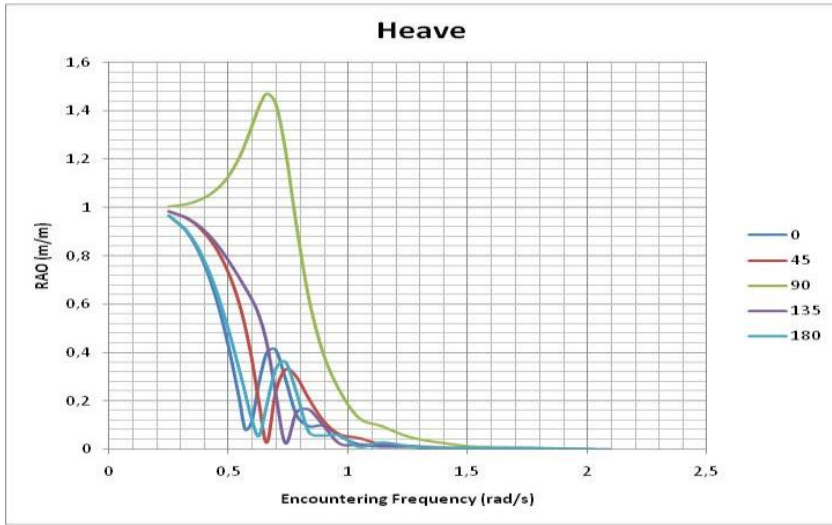

Figure 12. Heave RAO of a 50,000 DWT tanker

Results of computation on the rotational mode of motions, namely roll, pitch and yaw, for the 50,000 DWT tanker are presented in Figs. 13 - 15. The largest RAO of roll 
motion happen to be at the wave heading $90^{\circ}$, at a value of approximately $5.374 \mathrm{deg} / \mathrm{m}$. In the case of pitch motion, maximum RAO is found to be some $1.39 \mathrm{deg} / \mathrm{m}$ due to bow quartering wave propagation of $135^{\circ}$. The maximum yaw RAO is reasonably low, only some $0.43 \mathrm{deg} / \mathrm{m}$ brought about also by $135^{\circ}$ wave.

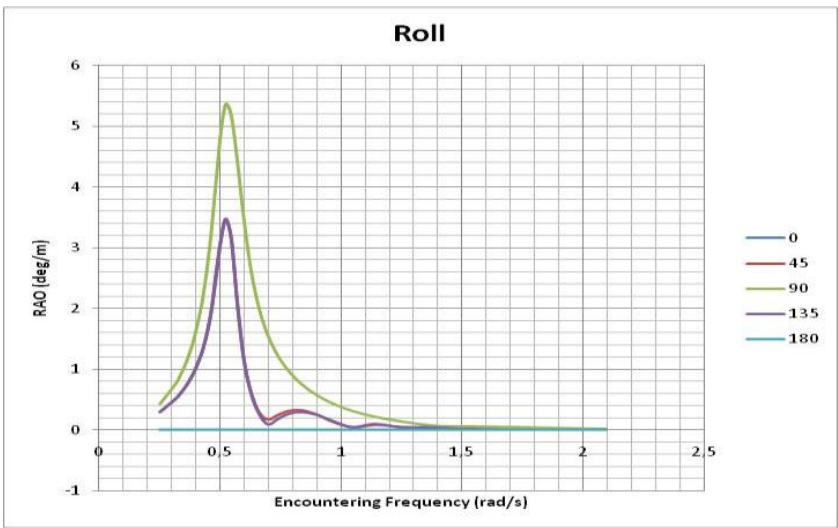

Figure 13. Roll RAO of a 50,000 DWT tanker

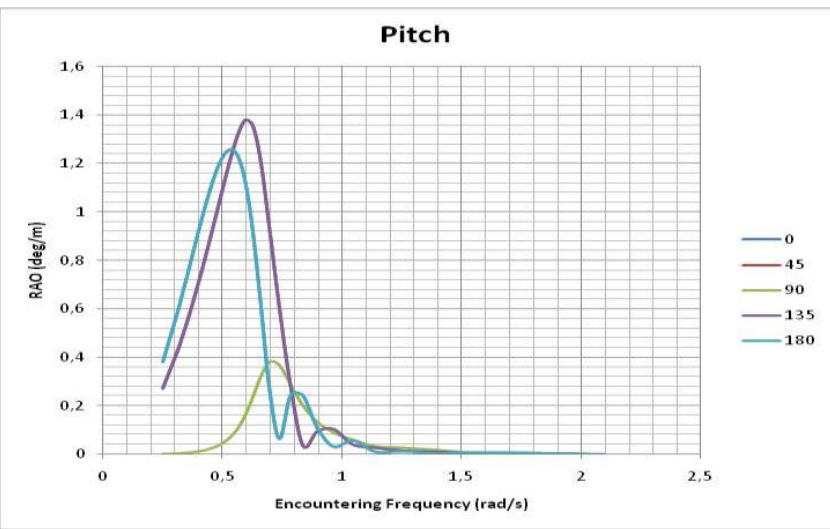

Figure 14. Pitch RAO of a 50,000 DWT tanker

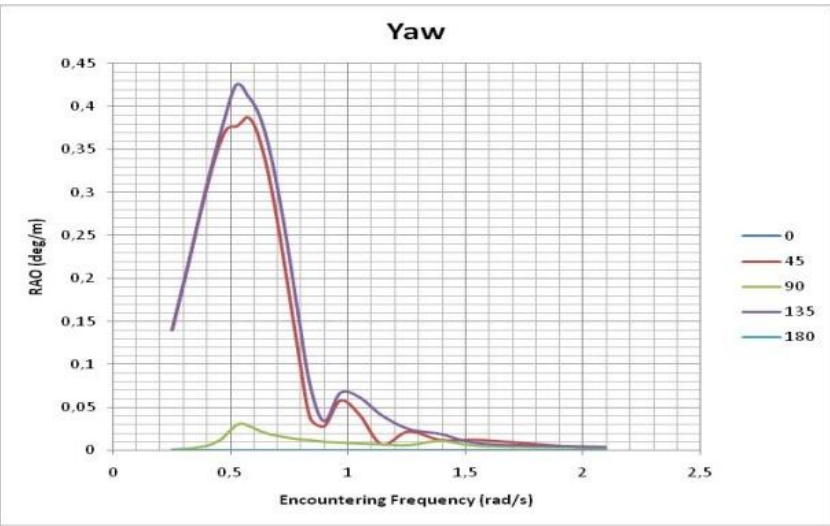

Figure 12. Yaw RAO of a 50,000 DWT tanker

\subsection{Tension Analysis on the Mooring Line}

Analysis of tension related to the mooring tensile strength was accomplished by the assistance of a software based on dynamic analysis in time domain. The analysis was performed on the 6 mooring lines induced by the environmental loading propagating in the directions of $0^{\circ}, 90^{\circ}$, and $180^{\circ}$. The analysis uses time history simulation and run for 3 hours or 10,800 secs in accordance with the provisions of OCIMF. Further, the simulations were also conducted for the cases of high and low tides.

Mooring lines used in this analysis are nylon ropes with a diameter of $50 \mathrm{~mm}$. MBL of the rope amounted 348.34 $\mathrm{kN}$. The mooring lines are considered safe when the maximum applied tension is less than the MBL divided by the safety factor of 2.2 as required by OCIMF. The following tables, shows the maximum tension and the ratio of MBL/ Maximum tension at each line based on simulation result for three environmental load $\left(0^{\circ}, 90^{\circ}\right.$ and $\left.180^{\circ}\right)$ at low and high tide for $10,000-50,000 \mathrm{DWT}$ mooring configuration as mention above.

Table 3. Mooring line tensions due to $0^{\circ}$ environmental load at high tide

\begin{tabular}{|c|c|c|}
\hline Line No & Max Tension $(\mathbf{k N})$ & MBL/Max Tens \\
\hline 1 & 28.3 & 12.3 \\
\hline 2 & 36.9 & 9.4 \\
\hline 3 & 64.9 & 5.4 \\
\hline 4 & 81.5 & 4.3 \\
\hline 5 & 33.3 & 10.5 \\
\hline 6 & 25.1 & 13.9 \\
\hline
\end{tabular}

Table 4. Mooring line tensions due to $0^{\circ}$ environmental load at low tide

\begin{tabular}{|c|c|c|}
\hline Line No & Max Tension $(\mathbf{k N})$ & MBL/Max Tens \\
\hline 1 & 28.0 & 12.4 \\
\hline 2 & 36.1 & 9.7 \\
\hline 3 & 54.9 & 6.3 \\
\hline 4 & 77.5 & 4.5 \\
\hline 5 & 31.5 & 11.1 \\
\hline 6 & 24.3 & 14.3 \\
\hline
\end{tabular}

Table 5. Mooring line tensions due to $90^{\circ}$ environmental load at high tide

\begin{tabular}{|c|c|c|}
\hline Line No & Max Tension $(\mathbf{k N})$ & MBL/Max Tens \\
\hline 1 & 117.5 & 3.0 \\
\hline 2 & 152.2 & 2.3 \\
\hline 3 & 155.6 & 2.2 \\
\hline 4 & 145.1 & 2.4 \\
\hline 5 & 40.4 & 8.6 \\
\hline 6 & 28.5 & 12.2 \\
\hline
\end{tabular}

Table 6. Mooring line tensions due to $90^{\circ}$ environmental load at low tide

\begin{tabular}{|c|c|c|}
\hline Line No & Max Tension $(\mathbf{k N})$ & MBL/Max Tens \\
\hline 1 & 116.2 & 3.0 \\
\hline 2 & 150.9 & 2.3 \\
\hline 3 & 154.8 & 2.3 \\
\hline 4 & 143.3 & 2.4 \\
\hline 5 & 39.8 & 8.8 \\
\hline 6 & 27.2 & 12.8 \\
\hline
\end{tabular}


Table 7. Mooring line tensions due to $180^{\circ}$ environmental load at high tide

\begin{tabular}{|c|c|c|}
\hline Line No & Max Tension (kN) & MBL/Max Tens \\
\hline 1 & 22.6 & 13.1 \\
\hline 2 & 36.1 & 9.7 \\
\hline 3 & 83.1 & 4.2 \\
\hline 4 & 67.9 & 5.1 \\
\hline 5 & 33.9 & 10.3 \\
\hline 6 & 25.8 & 13.5 \\
\hline
\end{tabular}

Table 8. Mooring line tensions due to $180^{\circ}$ environmental load at low tide

\begin{tabular}{|c|c|c|}
\hline Line No & Max Tension (kN) & MBL/Max Tens \\
\hline 1 & 24.1 & 14.5 \\
\hline 2 & 31.4 & 11.1 \\
\hline 3 & 79.5 & 4.4 \\
\hline 4 & 53.0 & 6.6 \\
\hline 5 & 31.7 & 11.0 \\
\hline 6 & 25.3 & 13.8 \\
\hline
\end{tabular}

From Tables 3 to 8 it can be seen that at the high tide, maximum tension occurs at line 3 on $90^{\circ}$ incoming environmental load, while the lowest maximum tension occured at $180^{\circ}$ on line 1 during low tide. Either at low or high tide, the highest maximum tension occurs on $90^{\circ}$ incoming environmental load. There are no significant difference of $\max$ tension for $0^{\circ}$ and $180^{\circ}$ incoming environmental load between low and high tide. In average, tension at low tide was smaller than tension at high tide. By observing the ratio of MBL/Tension, it can be concluded that the designed configuration of mooring dolphin was safe for operation as there is no value below $2.2[3,9]$.

\subsection{Tension Analysis if a Mooring Line Disconnected}

To evaluate the safety of the mooring line configuration, a condition of broken rope was simulated. The condition of maximum tension for each line when particular single line was broken or failed was evaluated. The following tables shows the values of ratio $\mathrm{MBL} /$ maximum tension for various fail condition.

Table 9. Values of MBL/max tension for the case of mooring line-1 is disconnected

\begin{tabular}{|c|c|c|c|c|c|c|}
\hline \multirow{2}{*}{$\begin{array}{c}\text { Line } \\
\text { No }\end{array}$} & \multicolumn{3}{|c|}{ Low Tide } & \multicolumn{3}{c|}{ High Tide } \\
\cline { 2 - 7 } & $\mathbf{0}^{\mathbf{0}}$ & $\mathbf{9 0}^{\mathbf{0}}$ & $\mathbf{1 8 0}^{\mathbf{0}}$ & $\mathbf{0}^{\mathbf{0}}$ & $\mathbf{9 0}^{\mathbf{0}}$ & $\mathbf{1 8 0}^{\mathbf{0}}$ \\
\hline 2 & 9.2 & fail & 10.3 & 9.0 & fail & 9.7 \\
\hline 3 & 6.0 & fail & 4.9 & 5.4 & fail & 4.6 \\
\hline 4 & 4.1 & fail & 6.6 & 3.9 & fail & 6.0 \\
\hline 5 & 10.9 & fail & 11.0 & 10.5 & fail & 10.0 \\
\hline 6 & 13.9 & fail & 13.6 & 13.8 & fail & 13.3 \\
\hline
\end{tabular}

Table 10. Values of MBL/max tension for the case of mooring line- 2 is disconnected

\begin{tabular}{|c|c|c|c|c|c|c|}
\hline \multirow{2}{*}{$\begin{array}{c}\text { Line } \\
\text { No }\end{array}$} & \multicolumn{3}{|c|}{ Low Tide } & \multicolumn{3}{c|}{ High Tide } \\
\cline { 2 - 6 } & $\mathbf{0}^{\circ}$ & $\mathbf{9 0}^{\circ}$ & $\mathbf{1 8 0}^{\circ}$ & $\mathbf{0}^{\circ}$ & $\mathbf{9 0}^{\circ}$ & $180^{\circ}$ \\
\hline
\end{tabular}

\begin{tabular}{|c|c|c|c|c|c|c|}
\hline 1 & 12.0 & 1.8 & 13.2 & 11.9 & 1.8 & 13.1 \\
\hline 3 & 6.6 & 1.7 & 4.8 & 5.4 & 1.6 & 4.6 \\
\hline 4 & 4.1 & 1.6 & 6.6 & 3.9 & 1.6 & 6.0 \\
\hline 5 & 10.8 & 7.4 & 10.7 & 10.5 & 7.3 & 10.3 \\
\hline 6 & 13.9 & 13.0 & 13.0 & 13.7 & 12.3 & 12.8 \\
\hline
\end{tabular}

Table 11. Values of MBL/max tension for the case of mooring line- 3 is disconnected

\begin{tabular}{|c|c|c|c|c|c|c|}
\hline \multirow{2}{*}{$\begin{array}{l}\text { Line } \\
\text { No }\end{array}$} & \multicolumn{3}{|c|}{ Low Tide } & \multicolumn{3}{|c|}{ High Tide } \\
\hline & 0o & $90^{\circ}$ & $180^{\circ}$ & $\mathbf{0}^{\circ}$ & $90^{\circ}$ & $180^{\circ}$ \\
\hline 1 & fail & 2.5 & fail & fail & 2.6 & fail \\
\hline 2 & fail & 1.9 & fail & fail & 2.0 & fail \\
\hline 4 & fail & 5.9 & fail & fail & 5.7 & fail \\
\hline 5 & fail & 6.5 & fail & fail & 9.7 & fail \\
\hline 6 & fail & 9.7 & fail & fail & 6.7 & fail \\
\hline
\end{tabular}

Table 12. Values of MBL/max tension for the case of mooring line- 4 is disconnected

\begin{tabular}{|c|c|c|c|c|c|c|}
\hline \multirow{2}{*}{$\begin{array}{l}\text { Line } \\
\text { No }\end{array}$} & \multicolumn{3}{|c|}{ Low Tide } & \multicolumn{3}{|c|}{ High Tide } \\
\hline & $\mathbf{0}^{\circ}$ & $90^{\circ}$ & $180^{\circ}$ & $\mathbf{0}^{\circ}$ & $90^{\circ}$ & $180^{\circ}$ \\
\hline 1 & fail & 2.8 & fail & fail & 2.8 & fail \\
\hline 2 & fail & 2.2 & fail & fail & 2.2 & fail \\
\hline 3 & fail & 2.8 & fail & fail & 2.7 & fail \\
\hline 5 & fail & 5.4 & fail & fail & 5.5 & fail \\
\hline 6 & fail & 7.9 & fail & fail & 8.1 & fail \\
\hline
\end{tabular}

Table 13. Values of MBL/max tension for the case of mooring line-5 is disconnected

\begin{tabular}{|c|c|c|c|c|c|c|}
\hline \multirow{2}{*}{$\begin{array}{c}\text { Line } \\
\text { No }\end{array}$} & \multicolumn{3}{|c|}{ Low Tide } & \multicolumn{3}{c|}{ High Tide } \\
\hline 1 & 12.9 & 3.1 & 14.5 & 12.4 & 3.1 & 14.4 \\
\hline 2 & 10.2 & 2.1 & 10.9 & 9.9 & 2.2 & 11.0 \\
\hline 3 & 6.6 & 2.0 & 4.1 & 6.5 & 2.1 & 4.0 \\
\hline 4 & 4.8 & 2.0 & 6.7 & 4.8 & 2.1 & 6.8 \\
\hline 6 & 14.3 & 6.1 & 13.7 & 14.1 & 6.2 & 6.2 \\
\hline
\end{tabular}

Table 14. Values of MBL/max tension for the case of mooring line- 6 is disconnected

\begin{tabular}{|c|c|c|c|c|c|c|}
\hline \multirow{2}{*}{$\begin{array}{c}\text { Line } \\
\text { No }\end{array}$} & \multicolumn{3}{|c|}{ Low Tide } & \multicolumn{3}{c|}{ High Tide } \\
\hline 1 & 12.9 & fail & 13.2 & 12.4 & fail & 12.9 \\
\hline 2 & 10.2 & fail & 9.7 & 10.0 & fail & 9.7 \\
\hline 3 & 6.5 & fail & 3.8 & 6.3 & fail & 3.7 \\
\hline 4 & 4.9 & fail & 6.0 & 4.8 & fail & 5.9 \\
\hline 4 & 11.0 & fail & 10.2 & 10.6 & fail & 10.0 \\
\hline
\end{tabular}

From Table 9-14 it can be seen that when a single rope disconnect, will cause disruption of the tension of the rope to another. Fail indicates that the rope has been broken or disconnected. By observing the values of $\mathrm{MBL} / \mathrm{max}$ tension, for all direction of environmental load and the tide condition, it can be concluded that, the configuration of mooring dolphin will not be safe if only one rope disconnect.

\section{CONCLUSION}

The following remarks can be drawn from this paper:

1. Appropriate layout for mooring dolphin can be viewed 
from two aspects, namely horizontally and vertically. Vertically, as the elevation of the mooring dolphin ranged from $-14.2 \mathrm{~m}$ about LLWS (datum) to an elevation of $6.35 \mathrm{~m}$ LLWS (datum).

Horizontally, as the distance amongst the mooring dolphin - in one mooring system, as there are three terminal / configurations of mooring dolphin in a single jetty in this study. For each configuration there are 6 mooring dolphin and 2 breasting dolphin. For configuration 1 on 10,000-50,000DWT as discussed in this paper, the distance between breasting dolphin is $62.21 \mathrm{~m}$, while the distance between ships to the mooring dolphin is $40 \mathrm{~m}$. The distance between the mooring dolphin is $22.09 \mathrm{~m}$ and $16.5 \mathrm{~m}$, and the distance between the mooring dolphin to breasting dolphin is $45.35 \mathrm{~m}$.

2. The smallest value of MBL / tension ratio of mooring configuration (2.2) occurred on line 3 when the direction of loading was $90^{\circ}$ at high tide conditions. However, the value indicated that the mooring line is still in safe condition.

3. When a single line was disconnect from the mooring system, the simultion shows that the ratio of MBL/Maximum tension indicated that the mooring system is fail. Therefore the configuration of mooring dolphin is unsafe for operation when a single line, at any location was broken or disconnected.

\section{ACKNOWLEDGEMENTS}

The authors would like to thank everybody who helped the preparation of this paper as well as providing environmental data for this study.

\section{REFERENCE}

1. Dolphins: Mooring, Breasting \& Berthing. May 11, 2013. Retrieved 20 August 2017 from https:// oceanandairtechnology.wordpress.com/2013/05/11 /dolphins-mooring-breasting-berthing/Sambodho, K.,

2. Zikra, M., Aldhiansyah, M.R.F. and Mulyadi, Y.: Design and modeling pile breakwater for LNG jetty at senoro field, Central Sulawesi. Applied Mechanics and Materials, V836, pp. 227-232, 2016

3. OCIMF: Mooring Equipment Guidelines, $3^{\text {rd }}$ Ed. Oil Companies International Marine Forum (OCIMF). Witherby Seamanship International, London, England. 2009

4. Google: Google Maps. Retrived 24 Oktober 2016 from www.google.co.id/maps

5. USACE: Shore Protection Manual, Vol I and II, $4^{\text {th }}$ Ed. U.S.Army Corp Engineering. Missisipi, 4th ed., 1984

6. Zikra, M., Hashimoto, N., Yamashiro, M., Yokota, M. and Suzuki, K.: Analysis of directional wave spectra in shallow water area using video image data. Coastal Engineering Journal, V54, I03, pp. 1250020, Sep. 2012

7. Mustain, M.: Amplitude variation with offset: case history in water table and lithological reflection. IOSR Journal of Applied Geology and Geophysic, V2, I7, pp. 51-58, 2014

8. Djatmiko, E.B.: The Behavior and Operability of Ocean Structures in Random Waves. ITS Press, Surabaya, 2012 (in Indonesian)

9. Handayanu, Swamidas, A.S.J. and Booton, M.: Behaviour of tension foundation for offshore structures under extreme pull-out loads. Proc. $18^{\text {th }}$ Int. Conf. on Offshore Mechanics and Arctic Engineering, St. John's, Newfoundland, Canada, July 11-16, 1999 